\title{
Study on the Influence Path of Sustainable Development of Green Building in Tianjin
}

\author{
Yihong Wang ${ }^{1}$, Yaxuan $\mathrm{Li}^{1{ }^{1, *}}$ \\ ${ }^{1}$ Tianjin University of Technology, School of Management, 300384 Tianjin, China
}

\begin{abstract}
This paper uses the qualitative comparative analysis method to define the conditional variables and the outcome variables of the impact path of the sustainable development of green buildings in Tianjin. Secondly, the paper analyzes the relationship between the conditional variables and the outcome variables to pave the way for the subsequent suggestions on the sustainable development of green buildings. Finally, by assigning values to the cases, the truth table of the impact path of sustainable development of green buildings is generated, the impact path is established, and the impact path is analyzed through the three aspects of the government, technology and enterprises.
\end{abstract}

\section{Introduction}

At present, China's economic development has entered a new normal. The energy demand is increasing rigidly, resource and environmental problems are still one of the bottlenecks restricting economic and social development. Energy conservation and emission reduction are still grim and arduous.

The comprehensive promotion of green building is a major measure to promote the transformation, upgrading and rapid development of China's construction industry. This paper points out the existing problems in the development of green buildings through the search and research of influencing factors. It paves the way for the continuous improvement of green buildings and the transformation and upgrading of buildings in Tianjin. The promotion of green building will accelerate the development of the modernization of the construction industry, and bring great environmental, economic and social benefits.

\section{Research design and methods}

\subsection{Literature Research on Sustainable Development of Green Buildings}

Most articles on the sustainable development of green building research, will affect the sustainable development of green building factors are divided into policy factors, green building participants factors, green building materials factors, technical factors in four areas, but the division is not perfect, because in the development process, there are still economic factors such as cost, so the influencing factors need to continue to explore.

Scholars believe that the construction personnel themselves lack of green consciousness, the lack of green consciousness of management personnel in the construction, can not be a good application of green technology $y^{[1-2]}$. Another scholars believe that the development of green construction industry is still very short, its own certification system is not perfect, and there are still great misunderstandings in the new green building materials ${ }^{[3-4]}$. Finally, there is no systematic software for green building, and no technology and equipment for green building have been developed, which leads to the stagnation of green building development in China.

The above paper divides the influencing factors of green building into dimensions through four aspects of policy, society, economy and technology. However, in addition, there are factors such as management and labor, which lack other necessary factors, and have a great impact on the establishment of influencing paths, the analysis results of paths and the relationship between paths. Therefore, in order to conduct in-depth research on the sustainable development of green buildings, it is necessary to accurately collect the influencing factors and divide the dimensions correctly.

\subsection{Research methods of influence path}

Zhu believed that the QCA method can solve the problem of asymmetric causality. This kind of asymmetric thinking is more suitable for studying the pattern problem of achieving results in various situations ${ }^{[5]}$. The robustness of QCA analysis results is independent of the sample size, which is suitable for the study of small and medium sample size.

Therefore, considering the complexity of integrating the interaction of situational variables into the research development path, the application of QCA method has high applicability to the research of this problem. It can deal with the problems of symmetry and asymmetry at the same time, and is more stable than the traditional statistical 
analysis, which reduces the uncertainty of the results.

\subsection{Research logic}

\subsection{1 research content}

According to the research content, this paper establishes the logical framework of the study. Firstly, it studies the influencing factors and influencing paths of the sustainable development of green buildings. Then, it conducts on-the-spot investigation and verifies them. Finally, it summarizes the literature and the data of 23 cases in Tianjin in recent years, and collects the sample data. Then, through the QCA method, it establishes the influence path model, uses the critical path method to analyze and compare each path, and establishes the critical path, and finally draws the conclusion.

\subsection{2 case analysis and QCA research model}

Through the analysis of cases such as Tianjin Taida MSDI District Project, the first kindergarten project in the southern part of Tianjin Eco-city, the comprehensive teaching building project of Binhai School of Tianjin No. 1 Middle School, and the third stage resettlement area project of Balitai demonstration small town in Tianjin Southern District. Through case screening, it identifies the influencing factors, summarizes the influencing factors of the sustainable development of green buildings, and establishes the flow chart of case analysis.

In this paper, the influence path of green building sustainable development is mainly studied by QCA method. After obtaining the influencing factors of green building sustainable development that have been identified, the influence path is established and analyzed through the determination of variables and random combination.

\section{Identification of Factors of Green Building}

This section first through literature research on green building, green building sustainable development, green building sustainable development influencing factors of literature search, analysis and reclassification. Through the research on the influencing factors in the literature, the influencing factors mentioned by the authors that affect the sustainable development of green buildings are screened, listed and summarized, and analyzed.

The study found that there are many kinds of influencing factors, but most of them can be divided into market, economy, policy, cost and other main factors. In addition, there are secondary factors such as management, ecological value, supply chain and so on. Thus, the influencing factors of green building sustainable development are not single, and the influencing factors will continue to be summarized and analyzed. so first of all, we should summarize the influencing factors of green building sustainable development, as shown in table1.
Table 1 Summary of influencing factor

\begin{tabular}{|c|c|c|}
\hline Influencing factors & $\begin{array}{c}\text { Number } \\
\text { of } \\
\text { references }\end{array}$ & Proportion \\
\hline $\begin{array}{c}\text { Imperfect State Incentive } \\
\text { Policy }\end{array}$ & 13 & $18.2 \%$ \\
\hline $\begin{array}{l}\text { Enterprise recognition is not } \\
\text { high }\end{array}$ & 11 & $13.6 \%$ \\
\hline $\begin{array}{l}\text { Lack of advanced technical } \\
\text { support }\end{array}$ & 10 & $11.7 \%$ \\
\hline $\begin{array}{c}\text { High cost of green building } \\
\text { development }\end{array}$ & 9 & $10.7 \%$ \\
\hline $\begin{array}{l}\text { Lack of knowledge of green } \\
\text { building by owners }\end{array}$ & 5 & $9.7 \%$ \\
\hline $\begin{array}{l}\text { Inadequate evaluation } \\
\text { standard system }\end{array}$ & 4 & $7.8 \%$ \\
\hline $\begin{array}{l}\text { The legal system of green } \\
\text { building is not perfect and } \\
\text { lacks supervision and } \\
\text { supervision }\end{array}$ & 4 & $4.9 \%$ \\
\hline $\begin{array}{l}\text { Limited type, insufficient } \\
\text { quantity and single form of } \\
\text { green materials }\end{array}$ & 3 & $3.9 \%$ \\
\hline
\end{tabular}

\subsection{Study on Conditional Variables of Influencing Factors}

QCA has gradually been widely used in comparative politics, historical sociology, journalism and communication, economics and information science and other disciplines. Its application modes include clear set (csQCA), fuzzy set (fsQCA) and multi-valued set (msQCA) qualitative comparative analysis. Among them, csQCA is suitable for dealing with binary assignment variables. There is a relatively direct and clear correspondence between the causal variables selected in this paper, and the binary assignment of 0 or 1 can be carried out when encoding. Therefore, csQCA is used as the research method. Li believes that the research steps of QCA are mainly as follows ${ }^{[6]}$ :

The first step is to divide the conditional variable and the result variable into two parts according to certain standards, construct the truth table of 23 green building cases, and conduct the contradiction configuration test.

Step 2: Using fsQCA3.0 software, based on different outcome variables, the necessity of single variable for conditional variables is analyzed.

Step 3: Based on different outcome variables, the clear set operation is performed on all conditional variables, and Delete and code is selected. According to the default case frequency threshold 1 and consistency threshold 0.8 of the system, all logical remainders are deleted to obtain three schemes.

The fourth step: the intermediate scheme as the analysis standard, combing different conditional path combination, using Boolean minimization principle to simplify the results, and through the discussion of the results and cases, the preliminary conclusions are drawn. 
The fifth step : select one to two conditional variables or outcome variables, according to the principle of dichotomy to make appropriate adjustments, robustness test, and the combination of different outcome variables conditional path analysis and discussion, the final type of influence mechanism.

\subsection{Variable definition}

Incentive policy (IP), technical support (TS), enterprise recognition (ER), evaluation standard system (ESS), and development cost (DC) are selected as the five most frequently mentioned factors. The influential factors are taken as the conditional variables, and the development of green building (DGB) is taken as the result variable. Other variables are no longer introduced.

Finally, the collected data of each case is assigned according to the above variable measurement method. Subsequently, this paper will construct the true value table of green building development, and identify the combination of conditions affecting the development of green building in each case according to the threshold.

\section{Research on Influence Path Based on Qualitative Comparative Analysis}

This chapter through the Ministry of Housing and UrbanRural Development of the People 's Republic of China, the Chinese government network, the National Development and Reform Commission of the People 's Republic of China, Tianjin Development and Reform Commission and other websites.

\subsection{Study on Truth Table of Green Building Sustainable Development Cases}

To find and select the case of 23 green building projects in Tianjin, by looking for the data of each case, assignment, and then through the fsQCA3.0 software for the construction of the green building sustainable development truth table, all combinations of conditional variables and outcome variables can be obtained.

Using binary data Boolean algebra has two conditions or states: true (or present) and false (or nonexistent). These two states are represented by cardinal number $2: 1$ indicates existence ; 0 indicates that it does not exist. A typical Boolean-based comparative analysis solves the existence / nonexistence of conditions for obtaining a result. Therefore, in Boolean analysis of social data, all variables, antecedent conditions and results must be a measure of nominal size, preferably binary. Interval scale measurement is transformed into multi-category nominal scale measurement. The nominal scale measurement with two or more categories is represented by several binary variables.

Boolean negation In Boolean logic, negation changes membership from 1 to 0 and from 0 to 1 . For example, negation of a clear set of men is a clear set of non-men. If the case has a Boolean score of 1 in the male group, it has a Boolean score of 0 in the non-male group ${ }^{[7]}$.
Use truth tables to represent data In order to use Boolean algebra as a qualitative comparison technology, it is necessary to reconstruct the original data matrix into a truth table. The idea behind the truth table is simple. Once the data are recoded as nominal scale variables and expressed in binary form (such as 1 and 0 ), the data must be classified into different numerical combinations under accidental conditions.

\subsection{Research on conditional variables from the perspective of consistency and coverage}

After the truth table is constructed, the necessity of single variable is analyzed by calculating the consistency and coverage of the single variable, so as to determine whether there is a sufficient or necessary relationship between the single variable and the result variable, and the consistency is used to judge. The consistency indicates the sufficient degree of the sufficient condition that the conditional variable or combination is the result variable. The higher the sufficient degree is, the higher the possibility that the conditional variable or combination is the condition that causes the result variable is. When the consistency index is greater than 0.8 , it is considered that the conditional variable $(\mathrm{X})$ is a sufficient condition for the result variable $(\mathrm{Y})$, that is, the emergence of the conditional variable can lead to the occurrence of the results. When the consistency index is greater than 0.9 , it is considered that $\mathrm{X}$ is a necessary condition for $\mathrm{Y}$.

It can be seen that the consistency and coverage of incentive policies, enterprise recognition, technical support and development costs are relatively large. Therefore, it is necessary to focus on establishing the formulation of incentive policies, increasing the development of high-tech green buildings, reducing the investment cost of enterprises, and increasing the recognition of enterprises. Moreover, the role of the evaluation standard system cannot be ignored, and a set of perfect evaluation standard system should be to make green buildings develop in a more healthy direction.

\subsection{Influence path analysis and enlightenment of green building sustainable development}

In this paper, the fsQCA3.0 software developed by Ragin et al. is used to analyze the truth table of the development data of 23 green building cases in Tianjin. According to the proposal of Ragin and Fiss, 0.8 is the consistent threshold to identify the conditional combination of the development of each green building. The case threshold is set to 1 . Finally, the clear set qualitative comparative analysis method is used to obtain three types of solutions : complex solution, intermediate solution and simple solution.

In the development of the construction industry, the enterprise to a certain extent affects the development, transformation and upgrading of the construction industry, and new, environmental protection, green building for the benefit of mankind, should become the final trend of the development of the construction industry, therefore, in order to let the enterprise more quickly recognize and 
accept the green building, the local government should actively popularize the knowledge of green building, especially in highly educated groups to vigorously promote the economic benefit, social benefit and environmental benefit of green building, improve the consciousness of the middle class to green building, and create an environment atmosphere for the development of green building is an important part of corporate social responsibility.

\section{Conclusion}

Promoting the sustainable development of green buildings plays a decisive role in the implementation of sustainable development. There are many influencing factors in the long-term sustainable development of green building. Therefore, this paper studies the influence path of sustainable development of green buildings in Tianjin based on qualitative comparative analysis. The basic conclusions are as follows. Conclusion 1: based on literature research and case analysis, the influencing factors are determined. Conclusion 2: Influence Path Based on Qualitative Comparative Analysis. On the basis of defining the influencing factors, 23 cases of green buildings in Tianjin are found. Through 0-1 assignment of each influencing factor in each case, the necessity of single variable for each conditional variable is analyzed, and the consistency and coverage of each variable are analyzed.

Under the background of green China, various industries and fields in the country are taking the road of energy conservation and environmental protection, which is also the only way for the sustainable development of the construction industry. Encouraged by relevant national policies, under the supervision of relevant laws and regulations, enterprises have a mature cost control system, the choice of new green and economic building structure forms, coupled with the adequate supply of green building materials and the support of advanced construction technology, which has laid a good foundation for the sustainable development of green buildings.

As a pioneer model city to carry out the national green building, Tianjin has pollution problems caused by traditional buildings in the development process, but as long as all fields can establish the concept of green building, strengthen the application of green building energy saving technology. I believe that in the near future, it will be able to fully realize the construction of green city. China's green building industry, environment-friendly and resource-saving society, social sustainable development, will have a good development prospect. Although this paper studies the influence path of sustainable development of green buildings in Tianjin, there are still some deficiencies due to the limited personal ability. For example, whether 23 cases can explain the influence path of sustainable development in Tianjin and whether more cases are needed for more accurate research need to be further verified.

\section{References}

1. Qiu Baoxing. Green building development errors and promotion path [J]. Building, 2019 (13) : 20-22.

2. Wang Hao. Analysis of sustainable development and influencing factors of green buildings [J]. Henan Building Materials, 2019 (06): 215-216.

3. Wang Wei. The restrictive factors and countermeasures in the promotion of green buildings in China [J]. Real estate, 2019 (08 ): 89-90.

4. Lin Changhua. The path mechanism of the impact of financial development on China's high-quality economic development [J]. Credit, 2020,38 (02): 7784

5. Zhu Hongli, Lin Zhimin. Configuration analysis of influencing factors for regional development of prefabricated buildings based on QCA [J]. Construction economy, 2020,41 (02):115-120.

6. Shen Junxin, Li Shuang, Zhang Jingyang. Research on influencing factors of big data industry development ability-based on fsQCA method [J]. Science and technology management research, 2019,39 (07): 140-147.

7. Ma Wenxuan, Xu Jian. Research on the influencing factors of emergency logistics system construction based on QCA [J]. Shanghai Management Science, 2019,41 (02): 18-22. 